\title{
The Effect of Mozart's Music on Social Learning Behavior of High School Students
}

\author{
Jose Maria G. Pelayo III \\ Social and Psychological Research Unit (SPRU), Systems Plus College Foundation, Angeles City, Philippines
}

\begin{abstract}
The researcher acknowledges the importance of creativity and innovation in terms of discovering more methods or strategies on improving intellectual growth of an individual, in this case, the researcher focuses on the social learning behavior of high school students, many high school students are vulnerable to low academic performance due to numerous factors. As the increase of high school students who have low academic performance, programs in improving and developing academic performance should be implemented along with instilling proper discipline and motivation to students. The researcher would like to discover other possible programs that could enhance learning and eventually improve academic performance.

Keywords: Mozart, effect, music, social learning behavior, students, classical, cognitive development, spatial temporal reasoning, Mozart effect phenomenon, supplementary methods for learning, environment conducive for learning
\end{abstract}

\section{Introduction}

The youth of today live in a world wherein numerous stimuli exist. These stimuli may either supplement or hinder their intellectual growth. The youth are surrounded by all of these stimuli and significantly divide their attention, resulting in low academic performance in school, an outcome undesired by their parents. An ideal student should be productive in all school activities, contributing to social development programs and mainly attaining high academic performance represented by high grades. The education of the youth is an important mission and should be continuously updated for supplementary programs that could improve and develop intellectual growth.

The researcher acknowledges the importance of creativity and innovation in terms of discovering more methods or strategies on improving intellectual growth of an individual, in this case, the researcher focuses on the social learning behavior of high school students. The researcher would like to discover other possible programs that could enhance learning and eventually improve academic performance.

About 15 years ago, a professor of psychology stirred up the music world with the idea that listening to Mozart could make you smarter. Before the decade was out, the work of Dr Frances H. Rauscher, professor of psychology at the university of Wisconsin Oshkosh, had brought forth a veritable flood of pop-psych books, tapes, and CDs promising in newspaper inserts and on television infomercials to boost your brain. One enterprising author even went so far as to trademark the phrase "the Mozart effect".

Jose Maria G. Pelayo III, Ph.D., professor, Social and Psychological Research Coordinator, Social and Psychological Research Unit (SPRU), Systems Plus College Foundation. 
As high school students of today, there are a lot of distractions that could disrupt study habits, review programs, and research specially when out of the school campus. Internet, games, media, sports, peers, social problems, and other types of entertainment play tug of war with the time for reading, research, and review. There is a need for supplements to aid the education of our youth. In this study, the researcher would like to discover if Mozart's music can elicit any form of behavior that would lead to learning, creating an environment that would be conducive for learning in the academic and social setting of high school students.

\section{Background of the Study}

Albert Bandura believed in "reciprocal determinism", that is, the world and a person's behavior cause each other, while behaviorism essentially states that one's environment causes one's behavior, Bandura, who was studying adolescent aggression, found this too simplistic, and so in addition he suggested that behavior causes environment as well. Later, Bandura soon considered personality as an interaction between three components: the environment, behavior, and one's psychological processes (one's ability to entertain images in minds and language).

The researcher would like to consult with Bandura's "reciprocal determinism" as one of the references for this study, if Mozart's music would have a significant effect on the social learning behavior of high school students. This would involve adolescent behavior, the environment, and psychological processes. In the pursuit of discovering additional methods that would enhance learning by eliciting any form of learning behavior on both academic setting and social setting of high school students, this study will test the "Mozart effect phenomenon" and its significant effects on the social learning behavior of high school students.

\section{Conceptual Framework}

If the environment of the youth, in their academic and social setting, would set a positive mood that would elicit any form of behavior that would lead to learning, then the probability of attaining good academic performance would be close at hand. This environment would be ideal for every student, inside or outside the classroom setting. This environment would create positive results for all students, academically and socially. The researcher would like to create that particular environment, fabricating an educational atmosphere that would be a catalyst to learning. The researcher would create an environment that would be ideal for educational institutions and will enhance the social learning behavior of every student. The researcher believes that the element needed in establishing that ideal environment for learning is music.

\section{Significance of the Study}

The researcher would like to attempt to discover different methods in improving the social learning behavior of high school students, utilizing essential tools to further develop academic performance. Taking into consideration the different possible factors that may improve learning among high school students, not only in the classroom but also outside the classroom setting. The study will serve as a reference for the administration and high school faculty of systems plus college foundation in establishing an ideal environment that would enhance students' learning, in academic and social settings, within the institution.

The study could also help tutorial services rendered by teachers in Angeles city, it could be implemented 
in study habits and private tutorial sessions. Elementary and high school public teachers could also benefit from the study by using Mozart's music and eliciting any form of behavior that would lead to learning of their students.

Classical music has been used for relaxation and meditation by many individuals for many years now. The researcher aims to discover if Mozart's music could create an environment that would elicit any form of behavior that would lead to learning. Other institutions in Angeles city could use the study as a reference to their education programs in their respective schools. Considering the fact that there are many high schools in Angeles city, all of them could benefit from the study.

The study could serve as a guideline for improving learning abilities of children in their nursery, kindergarten, and elementary stages. The school could create an ideal environment for these children so that they would learn faster and more efficiently. If Mozart's music could elicit any form of behavior leading to learning, then it would enhance the learning process of children, making them learn faster in their academic and social setting. In the early stages of education, any form of supplement that would make education efficient and effective should be taken into consideration. It is during these stages that education is a big influence on their growth and development. If the effects of Mozart's music could elicit any form of behavior leading to learning, then our young children would surely benefit from this study by creating an atmosphere conducive for fast and efficient learning.

\section{Scope and Limitation}

The study will focus on Mozart's music and the effect it has on the social learning behavior of high school students in systems plus college foundation, Angeles city. The researcher chose only Mozart's music because of the "Mozart effect phenomenon". This study will further validate if Mozart's music could have a significant effect on the social learning behavior of students in their academic and social setting.

The scope of the study will involve the social learning behavior of high school students in their academic and social setting, particularly in systems plus college foundation. There is already an existing culture in this institution and this study attempts to discover the effects of Mozart's music on the existing dynamics of the students, specifically in their social learning behavior. In this study, the researcher would like to discover if Mozart's music could elicit any form of behavior leading to learning. All participants of the study are high school students enrolled in systems plus college foundation, Angeles city. Only the social learning behavior of these students and Mozart's music will be involved in this study.

\section{Definition of Terms}

The definition of terms is as follows:

(1) Mozart's music - musical compositions of Wolfgang Amadeus Mozart ex. Piano concerto no. 23 in a major k.448 (presto) (7mins 53secs);

(2) Social learning behavior - any form of behavior of a student that may lead to learning in their social and academic environment;

(3) High school students - adolescents enrolled in systems plus college foundation high school department;

(4) Academic environment - the environment of the student during class; classroom setting;

(5) Social environment — the environment of the student during their free time, lunch break, recess. 


\section{Review of Related Literature}

In 1993, Dr. Frances H. Rauscher, professor of psychology at the University of Wisconsin Oshkosh, had a group of college students mentally unfold a piece of paper and try to identify its shape. She found that the students who had listened to a recording of Mozart's k.448 sonata were better and faster at the task. Dr. Rauscher published the results in the journal Nature in the same year. There were only two problems with the Mozart effect. One was that it did not last: The students only held on to their newly acquired spatial skills for 10 or 15 minutes. The other problem was that when other researchers tried to verify the effect, some just could not. So, over the years since, the idea that Mozart can make you smarter has lost much of its credibility. However, a recent study has found that the Mozart effect is real-but only for certain people. It definitely works for right-handed non-musicians.

\section{Effects of Music Training on Individuals}

Studies about the concept that music training enhances IQ have received a lot of attention from researchers. The report from Schellenberg is the first one to test this hypothesis directly with random assignment of a large sample of children $(n=144)$ to two different types of music lessons (keyboard or voice) or to control groups that received drama lessons or no lesson. IQ was measured before and after the lessons. Compared with children in the control groups, children in the music groups exhibited greater increases in full scale IQ. The effect was relatively small, but it generalized across IQ subtests, index scores, and a standardized measure of academic achievement. Unexpectedly, children in the drama group exhibited substantial pre- to post-test improvements in adaptive social behavior that were not evident in music groups.

Another concept that music training can improve verbal memory was tested in children. The results showed that children with music training demonstrated better verbal but not visual memory than did their counterparts without such training. When these children were followed up after a year, those who begun or continued music training demonstrated significant verbal memory improvement. Students who discontinued the training did not show any improvement. Contrary to the differences in verbal memory between the groups, their changes in visual memory were not significantly different. Consistent with previous findings for adults (Chan, Ho, \& Cheung, 1998), the results suggest that music training systematically affects memory processing in accordance with possible neuro-anatomical modifications in the left temporal lobe.

At present, much empirical research has been motivated by the hypothesis that formal training music has nonmusical benefits. It is now well established (for reviews see Schellenberg, 2005, 2006a) that taking music lessons is associated positively with performance on tasks that measure abilities in the domains of language (e.g., Marques, Moreno, Castro, \& Besson, 2007; Moreno et al., 2008; Patel \& Iversen, 2007), spatial reasoning (Hetland, 2000), mathematics (Vaughn, 2000), memory (e.g., Jakobson, Lewyeky, Kilgour, \& Stoesz, 2008; Lee, Lu, \& Ko, 2007) full-scale IQ (FSIQ; Schellenberg, 2004, 2006b), and virtually any other domain one chooses to study (e.g., Hughes \& Franz, 2007; Stoesz, Jakobson, Kilgour, \& Lewyeky, 2007). The simplest explanation of the available data is that children with high FSIQs are more likely than other children to take music lessons and to do well on any test they are given (Schellenberg, 2006b). Nonetheless, many scholars including Tierney, Bergeson, and Pisoni (2008) and most of the cited above, continue to promote the 
notion of links between music training and specific sub-areas of intellectual functioning, which is tantamount to failing to see the forest (i.e., The big picture) for the trees (i.e., minor details; see Schellenberg \& Peretz, 2008).

\section{Mozart Effect Phenomenon}

A study was conducted on the effect of music listening for performance on a 25-question portion of the analytical section of the graduate record exam by 72 undergraduate students (m age $21.9 \mathrm{yr}$.). Five levels of an auditory condition were based on Mozart piano sonata no. 3 (k.281), movement i (allegro); a rhythm excerpt; a melody excerpt; traffic sounds; and silence. Participants were randomly assigned to one of the stimuli. After a 5-min., 43-sec. (length of the first allegro movement) listening period, participants answered the questions. Analysis indicated participants achieved significantly higher mean scores after all auditory conditions than those in the silent condition. No statistically significant pairwise mean difference appeared between scores for the auditory conditions. Findings were interpreted in terms of an arousal framework, suggesting the higher means in all auditory conditions may reflect immediate exposure to auditory stimuli.

There is much attention that has recently been drawn to the possibly positive effects of listening to Mozart or other classical music on cognitive performance. Students listening to Mozart's piano music for 10 minutes before testing performed better on IQ spatial reasoning tasks than when they had listened to a relaxation tape or remained in conditions of silence. Repetitive music had no positive effect on spatial reasoning or short-term memory performance measured with 16 short-term memory items. While the effect of Mozart's classical music on intellectual performance of the students was consistent with the in the above studies, the neurophysiological basis of this effect has remained obscure.

Furthermore, present interests in associations between music and intelligence stem from two independent areas of research (Schellenberg, 2003). One focuses on the short-term effects of simply listening to music. The so called Mozart effect refers to the finding that passive listening to music composed by Mozart produces temporary increases in spatial abilities (Hetland, 2000b; Rauscher, Shaw, \& Ky, 1993). Subsequent studies indicate, however, that the Mozart effect is difficult to replicate (Chabris, 1999; Steele, Bass, \& Crook, 1999; Steele, Dalla Bella, et al., 1999) when evident, it can be attributed to differences in arousal and mood generated by different testing conditions (Husain, Thompson, \& Schellenberg, 2002; Nantais \& Schellenberg, 1999; Thompson, Schellenberg, \& Husain, 2001) compared with sitting in silence for 10 minutes, listening to Mozart induces more positive moods and relatively optimal levels of arousal, which leads to higher levels of performance on tests of spatial abilities.

Despite issues with face validity, the Mozart effect has been seriously discussed in such prestigious publications as science and nature, and still frequents the pages of respected psychology journals. At times, there have been problems replicating the basic effect, but it has been suggested by Rauscher, Shaw, and Ky (1998) that inconsistent results by other researchers can be attributed to methodological differences.

Although other researchers cited that because of multiple intelligences, the Mozart effect, and emotional intelligence theories have inadequate empirical support and are not consistent with cognitive neuroscience findings, these theories should not be applied in education. Proponents countered that their theories had sufficient empirical support, were consistent with cognitive neuroscience findings, and should be 
applied in education (Cherniss, Extein, Goleman, \& Weissberg, 2006; Gardner \& Moran, 2006; Rauscher \& Hinton, 2006). However, Gardner and Moran offered no validating evidence for multiple intelligences, Rauscher and Hinton concluded that "listening-to-Mozart" studies should be disregarded, and Cherniss, Extein, Goleman, and Weissberg agreed that emotional intelligence lacked a unitary empirically supported construct.

On the other hand, studies from Nantais and Schellenberg (1999) had no difficulty replicating the basic finding: That is, they found a significant increase in performance on spatial-temporal tasks for subjects that heard a musical piece; but, there was no marked difference between those that heard Mozart and those who heard Schubert. Likewise, other researchers (e.g., Ashby, Isben, \& Turken, 1999; Steele, Bass, \& Crook, 1999) also observed that changes in mood can have a significant effect on cognitive performance, and that the original experimental conditions (e.g., listening to Mozart, relaxation music, or silence) likely each have an effect on mood and arousal. As such, the argument emerged that observed performance differences may occur due to improvements in mood and arousal rather than from neurophysiological priming. In addition, Thompson, Schellenberg, and Husain (2001) reported that individuals that listened to Mozart performed better on spatial tasks, but also scored higher on positive mood and arousal ratings. Subjects that scored low on mood and arousal showed no effect of the music. By examining participant's spatial abilities after listening to a Mozart sonata (expected to produce positive mood), and an adagio by Albinoni (a sad piece), they were able to provide additional support for the arousal and mood hypothesis.

\section{Effects of Background Music on Individuals}

One large sample study of 20,000 people showed music changes mood and the changes in mood were very uniform. A large number of people listened to classical music by various composers from various musical periods and were asked how the music made them feel. Another study showed that the effects of mood varied from person to person depending on their musicality. Non-musical people enjoy music rarely and when they do, the enjoyment is slight, while semi-musical people enjoy music quite often and when they do, it is enjoyable to them, while musical people enjoy music rarely, due to discriminating tastes, but when they do, it is with the greatest intensity.

An eight month study was conducted by Frances H. Rauscher of the University of California at Irvine, in which 19 preschoolers, ranging in age from three to five, received weekly keyboard and daily singing lessons while another 15 preschoolers received no musical training at all (bower). At the start, middle and end of the study, the subjects were tested on five spatial reasoning tasks. After only four months, scores on the test to assemble a puzzle to form a picture improved dramatically for the group with the musical training, while the control group did not, even though both groups started out with the same scores. It can be understood that this kind of improvement may not be substantial enough to alter the way people are fundamentally taught, but its results cannot be ignored. Rauscher explains, "Music instruction can improve a child's spatial intelligence for a long time, perhaps permanently".

It is universally understood that people strive to learn to become wiser and more informed about the world around them. The more people learn, the more powerful they can become. It is the speed at which people learn that separates the geniuses from the average people from the learning disabled. Geniuses do not run into problems while learning, because they learn so fast. It is everyone else that could really use help. One solid way to increase the speed at which people learn is with music. People learn through music and their minds grow faster because of 
it. Some music, when implemented properly, can have positive effects on learning and attitude. Music is a powerful thing, and when we understand its significance, it can bring dramatic changes both positive and negative in our lives.

Music and the arts make what life worth living and without them, people lose hold of their culture and diversity. The ideal way to learn in the future would be to fully incorporate music into the curriculum of every school. If every school supported and encouraged their students to freely pursue music with the culture of music in their everyday lives, people would become much more efficient in their learning and would become much better students on the whole. Music is a power too greater for man to comprehend at this point but through further study man can learn how to better harness its power to use it to its full potential.

With its resulting improvements in spatial reasoning, music can also be a very helpful tool when actually implementing it into the classroom and involving it with learning basic curriculum. In New York city, a program called learning through an expanded arts program, or leap, has been going on for a while now in which music and the arts are implemented into the school curriculum to improve scholastic scores of children at all levels (dean and gross 614). One way in which music is implemented is with math. They call it "musical math" in which the teacher incorporates rhythm with counting and gaining a grasp on the fundamentals of math (618).

\section{Methodology}

In this study, the researcher would like to discover additional methods or programs that would help maximize the time the youth spend inside the school setting by discovering ways to establish a conducive environment that would elicit any form of behavior leading to learning. In line with this, the researcher would like to enhance the social learning behavior of the youth, with the use of Mozart's music, to ensure proper attitude and motivation and eventually improve academic performance.

\section{Research Design}

The study will use the descriptive - survey method because it deals with the current dynamics of high school students before the exposure to Mozart's music in systems plus college foundation. The conditions, trends, and culture of the students will be collected by the researcher in the academic and social setting. Since the study will involve observation over a period of time, specifically five days before the exposure to Mozart's music and 20 days while exposed to Mozart's music, the appropriate method that will be used is the longitudinal design or time series design under the descriptive — survey method during the exposure to Mozart's music in both academic and social settings.

The study requires a qualitative method that observes and documents the behavior of high school students in the academic and social environment. This method also gathers information in the study of creating an environment conducive for learning, with the use of Mozart's music.

\section{Participants of the Study}

Participants of the study are high school students enrolled in systems plus college foundation, in Angeles city from ages 12 to 16 years old. Random sampling is the method of choosing the participants since the researcher will observe both academic and social settings. The social setting of high school students is the common place of gathering in their recess, lunch break, and free time. The participants will be in and out of 
these particular places. On the other hand, in their academic setting, the researcher will observe the behavior of the second year students in the classroom setting during their personality development period. Random sampling is also used to determine which class will be involved in the study for a period of 20 days. The class will consist of 40 students and is chosen randomly before the start of the study.

\section{Instrumentation}

A research data form is used for documenting all data observed before and after the exposure of high school students to Mozart's music. The data consist of the current dynamics of high school students before exposure to Mozart's music and, specifically social learning behavior, all details of behavior leading to learning during the exposure to Mozart's music. A DVD player with two speakers will be used to play a CD of Mozart's music. The songs from the album of Mozart which will be used in this study are:

(1) Symphony no.40 in g minor k.550 (molto allegro);

(2) Overture "le nozze di figarro";

(3) 12 variations on "ah, vous dirai-je, maman" k.265;

(4) Horn concerto no.1 in d major k.412 (allegro);

(5) Flute concerto no.2 in d major k.314 (rondeu, allegretto);

(6) Litaniae de beata maria virgine in b flat major k.109 (sancta maria);

(7) Violin concerto no.1 in d major k.218;

(8) Piano concerto no.21 in c major k.467 "elvira Madigan";

(9) String quartet in b flat major k.458 "hunt" (allegro assai);

(10) Violin concerto no.5 in a major k.219 "il turco" (allegro aperto);

(11) Piano concerto no.23 in a major k.448 (presto).

Board games, reading materials, and puzzles are also used in this study during the observation while exposed to Mozart's music. The following materials were used: five chess boards, five rubix cubes, five crossword puzzles, and 15 science journals.

A journal is used for the compilation of all data from day one to day 20. The data come from the log book used in the actual observation during exposure to Mozart's music. Data are collected from observation, before the exposure to Mozart's music, for a period of five days is also compiled in this journal.

\section{Data-Gathering Procedures}

The data-gathering procedure used in the study is observation, specifically disguised observation. This observational technique is most appropriate for the study because in this case, the revelation of student's natural behavior while exposed to Mozart's music is vital information. These are very important data that could determine the effect of Mozart's music on the social learning behavior of high school students. The researcher needs to blend in the crowd and be one with them in order to achieve this objective. On the other hand, "emotional distance" must be present between the observer and the participants to ensure that there is no bias in gathering information and will maintain objectivity. This technique allows the researcher to better understand and interpret the observed data since the researcher is within the participants of the study.

The researcher acknowledges the current culture (behavior of students in both academic and social settings) that exists in systems plus college foundation. First, the students were observed in both the academic (classroom) and social (outside the classroom) settings in order to determine the dynamics of the high school 
students, before the exposure to Mozart's music. The researcher used disguised observation for a period of five days, one hour every day for both settings. All data are documented and stored for further reference in this study.

As we continue the research, the same two settings were observed while exposed to Mozart's music, an academic setting, which will be in the classroom during the personality development period, and the social setting, which will be outside the classroom, specifically the food court in the high school department during lunch break. Both settings will be observed one hour a day for 20 days while exposed to Mozart's music.

In the academic setting, the researcher quietly observes the students in the back row of the classroom, during the personality development period of a second year class from 3:00 pm to 4:00 pm, pretending to read a book while carefully documenting the behavior of the students as they are exposed to Mozart's music for one hour. All of the mentioned board games, reading materials, and puzzles are placed on a table in front of the room.

In the social setting, the researcher quietly observes in the corner part of the food court, during lunch break of high school students 12:00 nn to 1:00 pm, pretending to read a book while carefully documenting the behavior of the students as they are exposed to Mozart's music for one hour. All of the mentioned board games, reading materials, and puzzles are placed on a table near the entrance of the food court.

\section{Statistical Treatment of Data}

All of the data gathered in the log book used for documenting during the observation are compiled into one journal, the data are then arranged chronologically. The recorded data on the behavior of students are then analyzed if there is a significant change in behavior as the students are exposed to Mozart's music. Significant effects are represented by the changing frequency of any behavior that leads to learning while exposed to Mozart's music in comparison with the existing dynamics of the students before the exposure to Mozart's music.

\section{Presentation, Analysis, and Interpretation of Data}

The dynamics of high school students, before exposure to Mozart's music, in the academic and social setting during the observation for a period of five days is interesting. In the academic setting (classroom), students are observed to be quiet and reserved. Students just tend to do their own thing silently in their places. A very low percentage of students, $10 \%$, elicit behavior leading to social interaction and a $0 \%$ of the class elicit behavior leading to learning. Most of the students just sit down resting and sleeping for one hour. No significant activity is taking place and the students are just waiting for the next teacher to come to the next subject. No interaction with the observer is present.

Behavior of students in the academic setting:

(1) Sleeping;

(2) Resting;

(3) Minimal verbal communication;

(4) Looking outside the window;

(5) Daydreaming;

(6) Playing with fingers; 
(7) Picking of the nose;

(8) Brushing hair/grooming;

(9) Looking at face with small mirrors.

In the social setting (food court), students display high percentages of social interaction. They eat, talk, and group together for one hour. An average of $60 \%-70 \%$ of the students elicit behavior leading to social interaction. Almost everyone is communicating to one another but still no communication with the observer. On the other hand, there is no evidence of student behavior that leads to learning during this time period.

Behavior of students in the social setting:

(1) Eating/drinking;

(2) Buying food and drinks;

(3) Playing with friends;

(4) Verbal communication;

(5) Laughing/shouting;

(6) Singing/chanting;

(7) Grouped together;

(8) Running/ chasing each other;

(9) Using cellular phones, gadgets, mp3, psp, etc..

All of the observation procedures were done consistently by the same observer, on the same timetables, and on the same locations. Participants of the study are not in any way informed about the research study and its objectives. The observation was done as confidential as possible to ensure the natural behavior of the participants in the respective settings during the observation period. The data collected by the observer in both academic and social settings are also confidential.

After a five day observation period and successfully documenting the current dynamics of high students in the academic and social settings before the exposure to Mozart's music, the researcher continues with a 20 day observation period of the same participants in their respective environments while exposed to Mozart's music.

\section{Conclusions}

Before the exposure to Mozart's music: The dynamics of high school students in the academic setting, during the five day observation period, has shown to have a minimal number of students displaying behavior leading to learning. Presented are the averages of the observed behavior of high school students before the exposure to Mozart's music.

After the exposure to Mozart's music: However, in the academic setting, during the exposure to Mozart's music for a period of 20 days, there was an increase in percentages from day 16 to day 20 . Every student was eliciting two or more behaviors leading to learning. In comparison to day 1 to day 15 , the last five days, day 16 to day 20 , showed very high percentages of students that showed behavior leading to learning. To further illustrate higher percentages of students that showed behavior leading to learning during the day 16 to day 20 , the following data are presented representing the averages of the percentage of students that showed behavior leading to learning during this time frame. 


\section{Academic Setting}

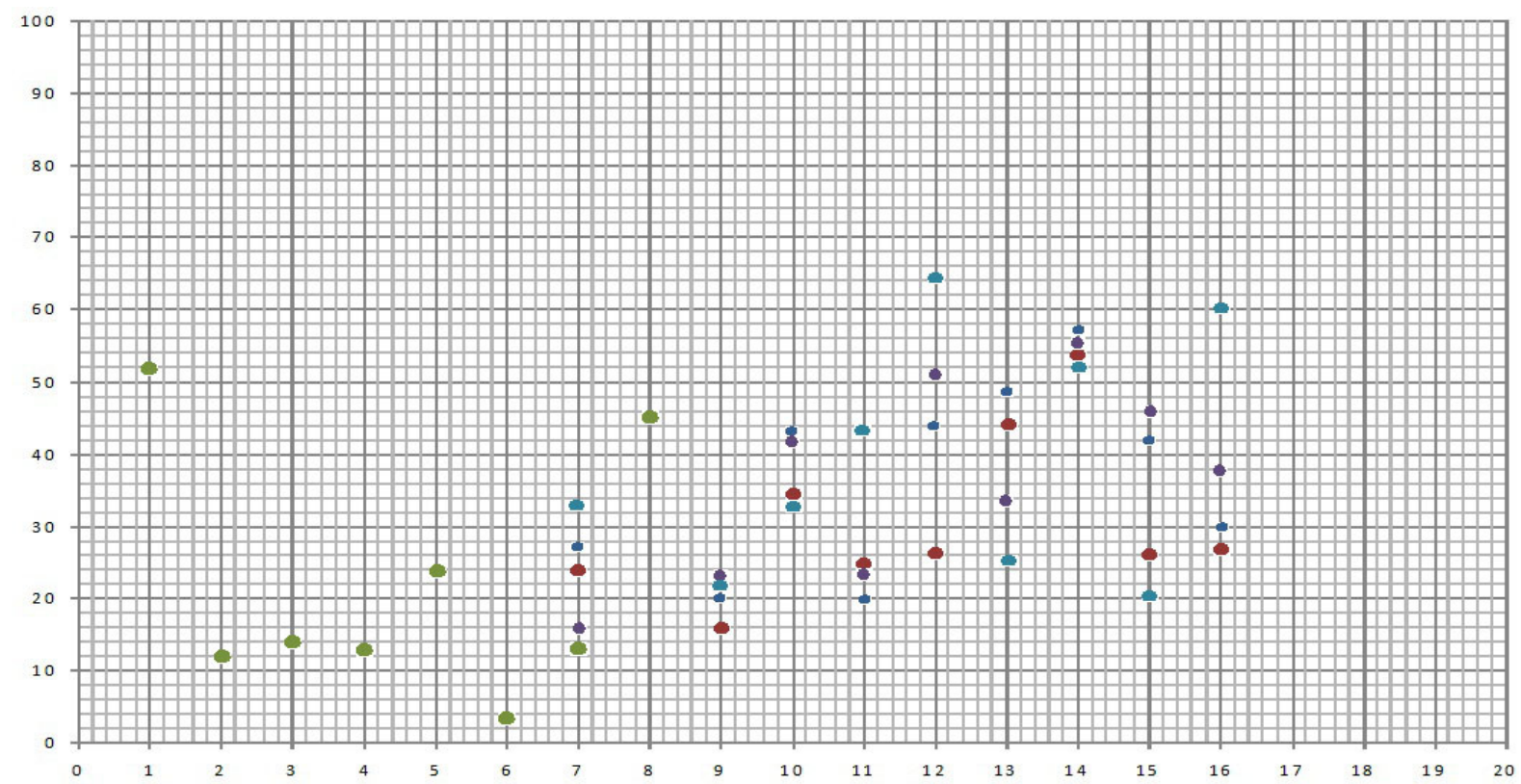

5 days without music

1st-5th day with music

6th-10th day with music

11th-15th day with music

16th-20th day with music

Figure 1. Academic setting.

Academic setting is as follows:

(1) Sleeping/resting;

(2) Looking outside the window;

(3) Playing with fingers/id/ watch/accessories;

(4) Reading/reviewing/studying;

(5) Brushing hair/grooming;

(6) Looking at mirrors;

(7) Drawing/writing;

(8) Talking;

(9) Playing chess;

(10) Playing the rubix cube;

(11) Solving the crossword puzzle;

(12) Reading the journals;

(13) Teaching/coaching/suggesting the answers/solutions/options to players;

(14) Observing other students play/solve;

(15) Asking questions about the game/puzzle;

(16) Reviewing/studying their lessons. 


\section{Social Setting}

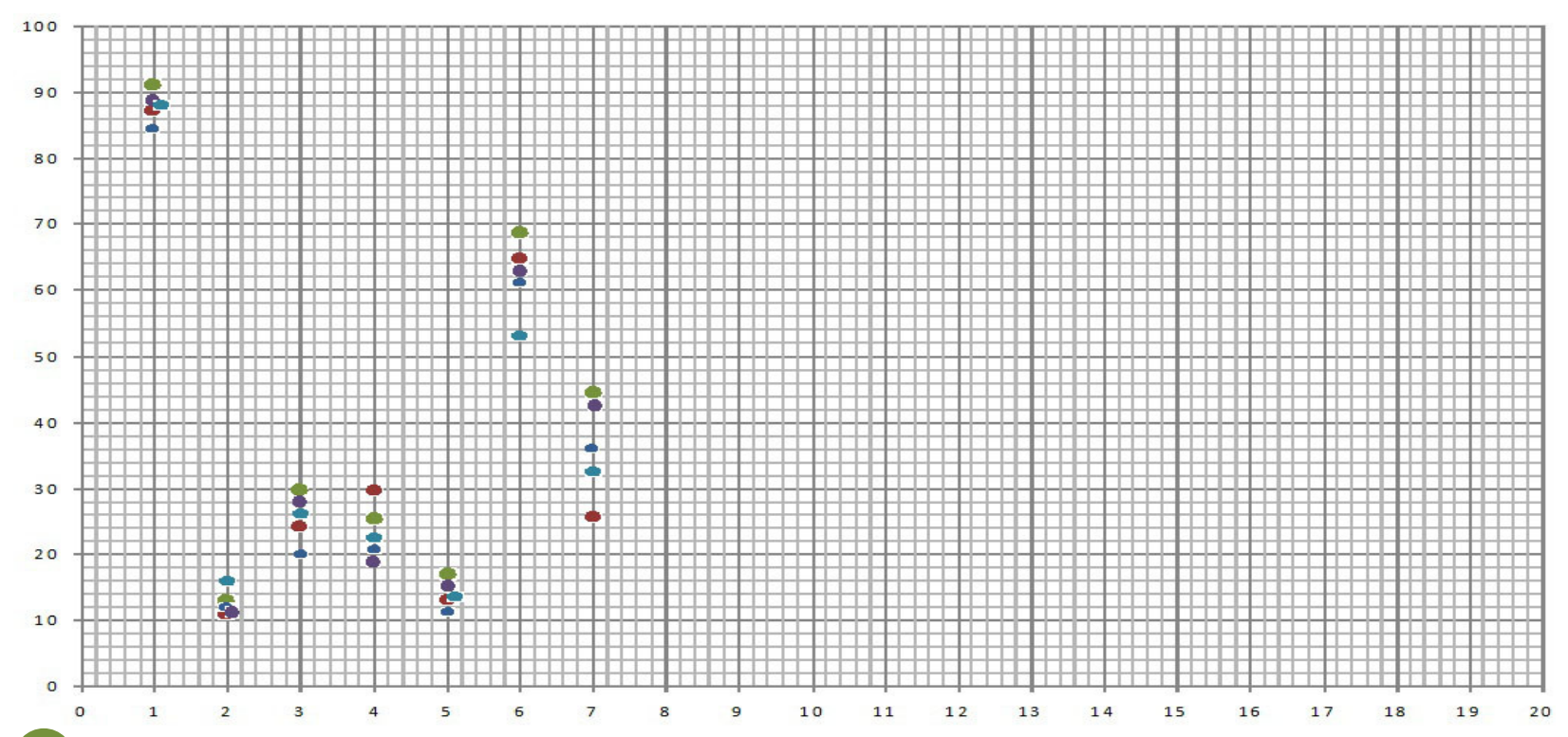

5 days without music

1 st-5th day with music

6th-10th day with music

11th-15th day with music

16th-20th day with music

Figure 2. Social setting.

Social setting is as follows:

(1) Eating/drinking/buying as a group;

(2) Reading/writing in a group;

(3) Playing with friends/running/chasing each other;

(4) Laughing/shouting in a group;

(5) Singing/chanting in a group;

(6) Using cellular phones, gadgets, mp3, psp, etc..

The researcher conducted a group discussion/interview on students in the academic setting focusing on the factors that made them move in the direction of behavior leading to learning. The group discussion/interview revolved around the question: Is the behavior of students leading to learning due to Mozart's music or other factors?

The discussion was very interesting, many students have cited out that Mozart's music at first made them sleepy and relaxed. Others said that the music made them imagine about the past and all the mistakes they made, it also made them think about happy memories and the time they spent with family and friends. Some female students said that Mozart's music made them imagine that they were in a fairy tale, in castles and celebrations, dancing as a princess. As they were more and more exposed to Mozart's music, they felt energized by the sudden change of tones and melodies, the sudden transitions in the volume of the music, the distinct and dynamic sound of the violin, and the overall impact of the orchestra as it suddenly comes out from the 
background to emphasize the song. Some students stated that they have heard this type of music on classic cartoons like Tom and Jerry, Tweety and Silvester, etc.. After continuous exposure to Mozart's music, they did not feel sleepy anymore, they wanted to do something. Other students have cited that they were carried away with the music, the tempo makes you want to stand up and conduct the orchestra, the music made them wave their hands, nod their head, and tap their feet to Mozart's music. The music made them sway and follow the highs and lows of the pitch and tempo, it also made them feel like they were walking on clouds, flying and floating in the air.

The students cited that while they were listening to Mozart's music, they discovered that they could read and study at the same time, the music did not distract them while they were reading or studying. Some students have cited that when they were reviewing or studying their lessons in the past, they were bored and spent little time reviewing or studying. But other students stated that Mozart's music made them enjoy reading and studying because they were not bored. Some students claimed that Mozart's music made them feel they could do new things, it inspired them to try to learn how to play chess, to answer the crossword puzzle, and to solve the rubix cube. They cited that when they watch students playing chess, answering the crossword puzzle, and solving the rubix cube, the music inspired them to play, answer, and solve too. One particular student said that, somehow, while listening to Mozart's music and watching other students play, answer, and solve, it looked easy and enjoying. While students play, answer, and solve the materials, Mozart's music made them nod their heads, wave their hands, and tap their feet to the highs and lows of the music. This scenario projected a positive image on other students who were watching them, it made learning to play chess, answering the crossword puzzle, and solving the rubix cube easy and delightful, many students also agreed. That is why this particular student tried to learn to play chess, tried to answer the crossword puzzle, and tried to solve the rubix cube. To summarize the group discussion/interview, Mozart's music, at first, made them listen and relax, then, with continuous exposure, made them energized and inspired to do things, it also made reviewing/reading/studying enjoyable, it established a setting or scenario that learning is easy and delightful, it created an environment conducive to learning.

\section{References}

Allen, L., \& Santrock, J. (1993). The contexts of behavior psychology. Madison, W.I.: Brown \& Benchmark Press.

American Psychological Association. (19 August 2004). New research provides the first solid evidence that the study of music promotes intellectual development. Retrieved from sciencedaily.com

Bandura, A. (1975). Social learning \& personality development. N.J.: Holt, Rinehart \& Winston, Inc..

Bandura, A. (1977). Social learning theory. New York: General Learning Press.

Bandura, A. (1997). Self-efficacy: The exercise of control. New York: W. H. Freeman.

Boeree, C. G. (2006). Albert Bandura 1925-Present. New York: General Learning Press.

Bruer, J. T. (2000). In search of ... Brain-based education. Kappan Professional Journal (Online), 80.

Cassity, H. D., Henley, T., \& Markley, R. (2007). The Mozart effect: Musical phenomenon or musical preference? A more ecologically valid reconsideration. Journal of Instructional Psychology, 34(1), 13.

David, R., \& Posts, T. (2009). "Mozart effect”. New York: General Learning Press.

Day, K. (2004). Music and the mind: Turning the cognition key. Observer Online, October 21, 2004.

Edward, A. R., \& Kenneth, H. S. (2009). The Mozart effect: Evidence for the arousal hypothesis, perceptual and motor skills. Missoula, 107(2), 396.

Evans, R. I. (1989). Albert Bandura: The man and his ideas: A dialogue. New York: Praeger.

Haggbloom, S. J., Warnick, R., et al. (2002). The 100 most eminent psychologists of the 20th century. Review of General Psychology. 
Hallam, C., \& Thaut (Eds). (2008). The Oxford handbook of music psychology. Oxford: Oxford University Press.

Ho, Y., Chan, A., \& Cheung, M. (2003). Music training improves verbal but not visual memory: Cross-sectional and longetitudinal explorations in children, University Of Hong Kong. Neuropsychology, 17(3), 439-450.

Honing, H. (2006). On the growing role of observation, formalization and experimental method in musicology. Empirical Musicological Review.

Jenkins, J. S. (2001). The Mozart effect. Journal of the Royal Society of Medicine, 94(4), 170-172.

Kane, M., Conway, A., Miura, T., \& Colflesh, G. (2007). Working memory, attention control, and the n-back task: A question of construct validity. Journal of Experimental Psychology: Learning, Memory and Cognition, 33(3), 615-622.

Levitin, D. J. (2006). This is your brain on music: The science of a human obsession. New York: Dutton.

Lynn, W. (2006). Inadequate evidence for multiple intelligences, Mozart effect, and emotional intelligence theories. Educational Psychologist, 41(4), 247.

Purwins, \& Hardoon. (2009). Trends and perspectives in music cognition research and technology. Connection Science.

Rudi, C., Sarah, J. W., \& Margot, P. (2006). No evidence for the Mozart effect in children. Music Perception, $23(4), 305$.

Schellenberg, E. G. (2004). Music lessons enhance IQ. Psychological Science, 15.

Schellenberg, E. G. (2008). Commentary on "Effects of early musical experience on auditory sequence memory" by Adam Tierney, Tonya Bergeson, and David Pisoni. Empirical Musicology Review, 3(4).

Snyder, B. (2000). Music and memory: An introduction. The MIT Press.

Steele, K. M. (2000). Arousal and mood factors in the "Mozart effect": Perceptual and motor skills. New York: General Learning Press.

Synnove, C., Pia, R., Denis, A., \& Ilka, L. (1997). Learning and memory. Neuro Report, 8(13).

Thomas, A. (2000). The Mozart effect: A closer look. New York: General Learning Press.

Thompson, W. F., Schellenberg, E. G., \& Husain, G. (2001). Arousal, mood, and the Mozart effect. Psychological Science.

William, F. T. (2009). Music, thought, and feeling: Understanding the psychology of music. Oxford: Oxford University Press. 